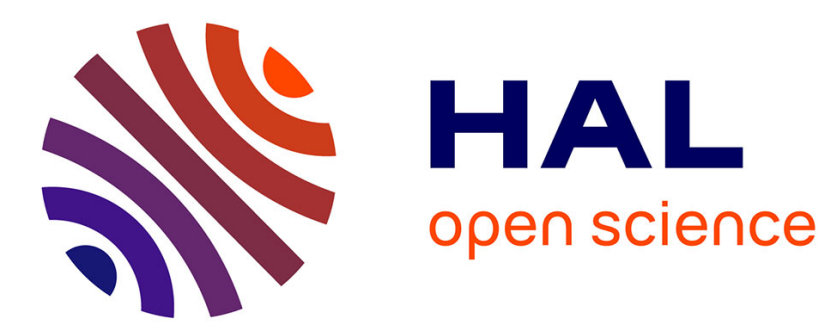

\title{
DETERMINATION OF THE OPTICAL PENETRATION DEPTH IN TUMORS FROM BIOPSY SAMPLES
}

P. Lenz

\section{- To cite this version:}

P. Lenz. DETERMINATION OF THE OPTICAL PENETRATION DEPTH IN TUMORS FROM BIOPSY SAMPLES. Journal de Physique IV Proceedings, 1991, 01 (C7), pp.C7-217-C7-220. 10.1051/jp4:1991756 . jpa-00250998

\section{HAL Id: jpa-00250998 https://hal.science/jpa-00250998}

Submitted on 1 Jan 1991

HAL is a multi-disciplinary open access archive for the deposit and dissemination of scientific research documents, whether they are published or not. The documents may come from teaching and research institutions in France or abroad, or from public or private research centers.
L'archive ouverte pluridisciplinaire HAL, est destinée au dépôt et à la diffusion de documents scientifiques de niveau recherche, publiés ou non, émanant des établissements d'enseignement et de recherche français ou étrangers, des laboratoires publics ou privés. 


\title{
DETERMINATION OF THE OPTICAL PENETRATION DEPTH IN TUMORS FROM BIOPSY SAMPLES
}

\author{
P. LENZ \\ INSERM U. 281, 151 Cours Albert Thomas, F-69003 Lyon, France
}

\begin{abstract}
The laser treatment of malignant tumors by photochemotherapy encounters several physical problems one of which is insufficient knowledge of the light penetration. Since the penetration depth may vary considerably from tumor to tumor it must be measured before the treatment in order to allow one to achieve a well defined photochemical effect. The method proposed here consists of two steps :

1 - Each tumor is characterized individually by two parameters which are obtained by goniometric measurement of the light crossing a small sample $\left(1 \mathrm{~mm}^{3}\right)$. These parameters can be easily determined in a clinical environment but provide no direct information on the light distribution in the bulk.

2 - The above parameters are related with the effective penetration depth for geometries and wavelengths of practical relevance. The relationship is established experimentally by multiple measurements in phantoms which are composed so as to approach closely the optical properties of tumors.
\end{abstract}

\section{DEFINITION OF THE OPTICAL CHARACTERISTICS}

The device shown in fig. 1 is used to measure the optical characteristics of tissues as well as of phantoms. A sample is contained between parallel glass plates separated by a distance of $0.5 \mathrm{~mm}$, within a metal disc having a conical hole. The borders of this hole are inclined at $45^{\circ}$. The sample volume so defined is as small as $1 \mathrm{~mm}^{3}$. Nearly collimated light $\left(2 \times 2.5^{\circ}\right)$ from an incandescent lamp and a monochromator (wavelength $630 \mathrm{~nm}$, bandwidth $16 \mathrm{~nm}$ ) is incident at an angle of $45^{\circ}$ onto the glass plates. Transmitted light is detected with an angular resolution of $3.2^{\circ}$ by a photodiode mounted on a goniometer $\left(0 \leq \vartheta \leq 90^{\circ}\right)$. The light intensity $I_{W}$, obtained with a waterfilled sample chamber and for $\vartheta=0$, is used to normalize the results. The geometry of this sample holder is rather particular, making an analytical description of $I(\vartheta)$ difficult. But the robust sandwich structure provides ease of manipulation; this is of great importance in view of clinical application.

28 human tumors of various origins (see legend to fig. 4) were examined. After excision the tumors were stored in a refrigerator (not frozen), in a closed vial to prevent drying but without any preparation, and examined mostly within one day ; this delay is not critical since even after several days no systematic variation of the optical characteristics could be detected. Generally the tumors were rather supple and therefore could be easily squeezed between the glass plates. In the rare cases where the tumors were harder, a disk of convenient size was first cut out and then introduced into the sample chamber. The smallness of the required sample volume allowed for multiple measurements of I $(\vartheta)$, typically twelve per tumor.

Owing to the orientation of the sample chamber the curves I $(\vartheta)$ are not symmetric with respect to the direction of the incident beam. To illustrate their overall behavior three cases are shown in fig. $2:$ strong transmission, resulting in a pronounced maximum close to the optical axis (one sample of tumor A); at the 
other extreme intense scattering which makes the sample surface almost lambertian (one sample of tumor $\mathrm{B}^{\prime}$ ) ; and finally a typical curve (one sample of tumor Q) approximately representing the majority of the tumor samples. In spite of their apparent diversity these curves have common features. It is found, indeed, that there is a relationship between the values $I(0)$ and $I\left(90^{\circ}\right)$ and the shape of the corresponding curve $I$

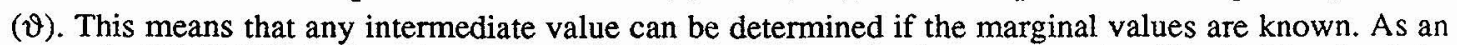
example, $\mathrm{I}\left(45^{\circ}\right) / \mathrm{I}(0)$ is plotted against $\mathrm{I}\left(90^{\circ}\right) / \mathrm{I}(0)$ for all examined tumor samples (fig. 3 ). The fit of the experimental points to a mean curve is quite suggestive. Similar curves are obtained for other intermediate angles.

This relationship allows one to draw two conclusions.

1 - It is possible to optically characterize tumors by only two parameters : $\mathrm{I}(0) / \mathrm{I}_{\mathrm{W}}$ which is called $\mathrm{F}$ and $\mathrm{I}\left(90^{\circ}\right) / \mathrm{I}_{\mathrm{W}}$ which is called $\mathrm{P}$.

2- The choice of the angle defining $\mathrm{P}$ is not critical. This is important because $\vartheta=90^{\circ}$ is an arbitrary value.

The 28 tumors are represented in a F, P - plane (fig. 4). As multiple measurements were made, the means. and the standard deviations are indicated. It is seen that the relative standard deviation is quite large (up to $58 \%$, for tumor $\mathrm{F}$ ). For a given tumor the variations of $\mathrm{F}$ and $\mathrm{P}$ are not independent, however : The mean of the corresponding correlation coefficients is -0.75 . This fact has important consequences as will be seen below.

\section{PHANTOMS}

To be representative of tumors, phantom materials must obviously have the same angular dependence of scattered intensity. After examination of numerous substances a mixture of calcium carbonate powder and starch particles (nearly spherical, $\approx 10 \mu \mathrm{m}$ diam.) suspended in glycerol, was chosen. As absorbers black and red ink, exhibiting low fluorescence, were used (their absorption coefficients at $630 \mathrm{~nm}$ were 680 and $1.2 \mathrm{~cm}^{-1}$ respectively). In 27 different mixtures, composed to cover approximately the area occupied by tumors in the F, P - plane, the relative concentrations of calcium carbonate ranged from 3 to $11 \%$; that of

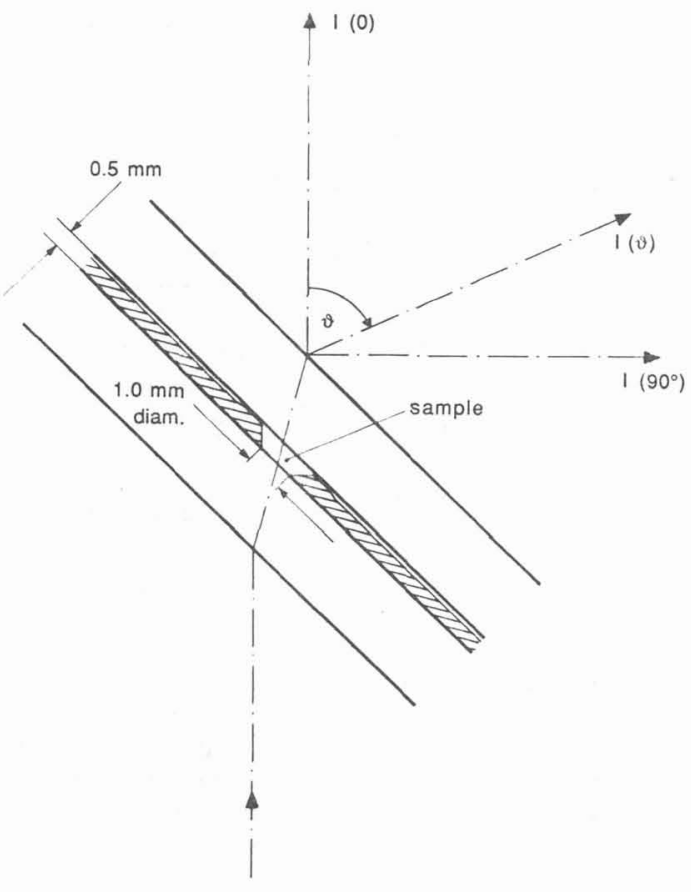

Fig. 1. Sample chamber used for the measurement of the optical characteristics.

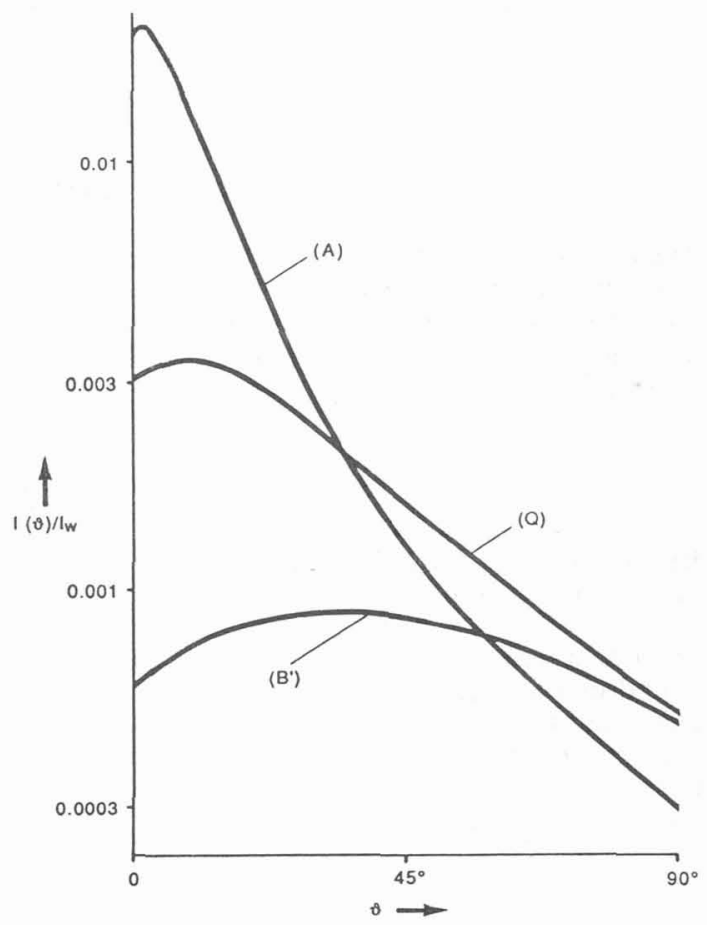

Fig. 2. Light transmitted by three representative tumor samples, as a function of angle. 
starch was always twice that of calcium carbonate, except for the lowest concentration where it was lower in order to give a better fit to the scattering curves of tumors. The concentrations of black and red ink were within the range 0 to $0.25 \%$ and 0 to $0.5 \%$ respectively.

The scattering curves $I(\vartheta)$ produced by these phantoms are very similar to those of the tumors, but not exactly the same, as is seen in fig. 3 . The circles representing phantoms lie slightly but systematically above the mean of tumors. This is the consequence of a compromise; in fact it would be possible to obtain a better agreement by enhancing the calcium carbonate concentration and reducing the starch concentration. However, this would accelerate sedimentation, which is not negligible in spite of the high viscosity of glycerol. The starch particles also sediment, but much more slowly. Another major source of error stems from the gradient of particle concentration which always forms in a liquid flow. Although the transport of the phantom mixture from the storage tank to the sample chamber was always performed slowly, using a wide ( $4 \mathrm{~mm}$ diam.) pipette, the concentration error was considerable. The overall error (relative standard deviation with about ten samples) in the measurement of $P$ ranges from about $0.6 \%$ at high concentrations to about $4 \%$ at low concentrations. For the parameter $F$ the figures are roughly two times higher. This is not very satisfactory.

\section{MEASUREMENT OF THE PENETRATION DEPTH}

Strictly speaking, the penetration depth $\mathrm{d}$ is defined only for a semiinfinite geometry and the associated exponential decrease of space irradiance $(S I \sim \exp (-x / d))$. In practice tissues are irradiated by light beams (in the following supposed circular and homogeneous), the diameter D of which is not necessarily much larger than $d$. Then the space irradiance on the optical axis is represented by a curve, the decreasing part of which is, for the same material, steeper than in the semiinfinite case and the slope of which is not constant. To obtain a well defined value of $\mathbf{d}$ the slope has to be taken at a well defined point. As such the point is chosen where the space irradiance equals the irradiance applied externally.

The space irradiance was measured in the phantoms mentioned above for $630 \mathrm{~nm}$ and for $\mathrm{D}=24 \mathrm{~mm}$ and 6 $\mathrm{mm}$. The volume of phantoms was 100 to $200 \mathrm{ml}$ so that the boundaries had virtually no influence on the results. Irradiation was accomplished by a slightly divergent light beam $\left(2 \times 7^{\circ}\right)$ from the side, across a perspex plate. The radiance was first measured within the phantoms on the optical axis, by means of a rotating miniature probe which provides a spatial resolution of $0.1 \mathrm{~mm}$ and then integrated over all directions so giving the space irradiance. $d$ is taken from each curve $\operatorname{SI}(x)$.

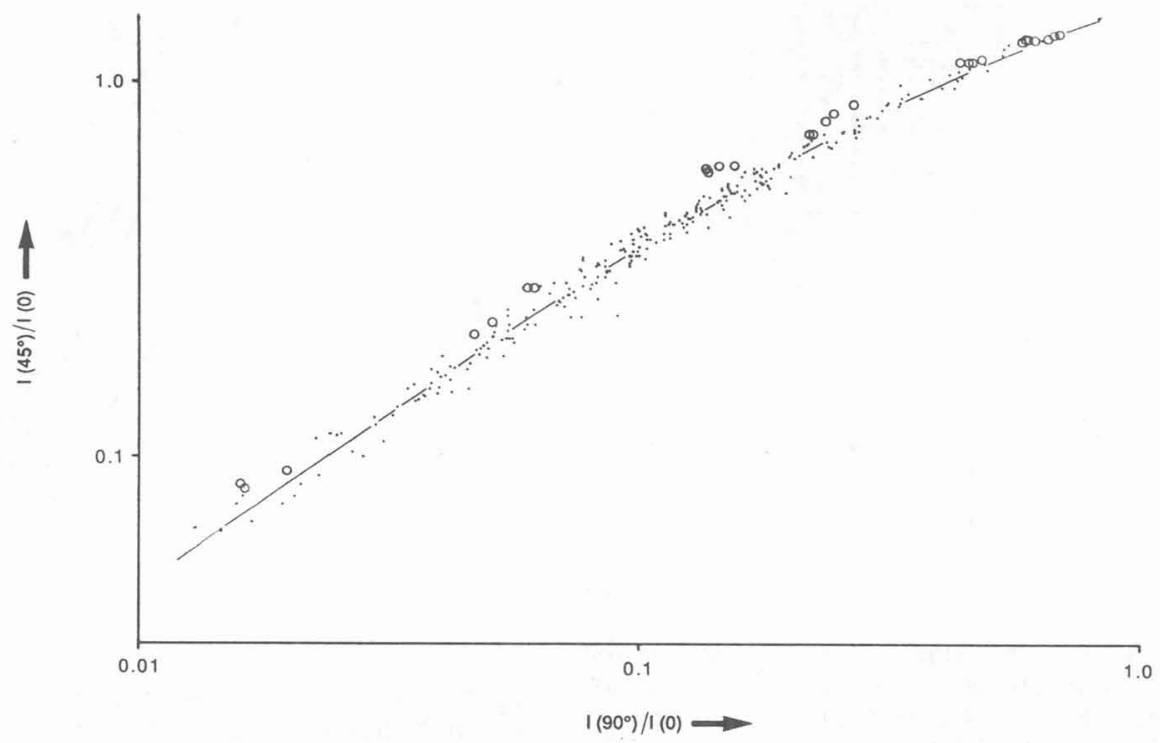

Fig. 3. Quantification of the shape of the scattering curves. Points are for tumor samples, and circles for phantoms. 


\section{RESULTS AND DISCUSSION}

Fig. 5 contains the same points characterizing the tumors as fig. 4 and in addition lines of constant penetration depth resulting from the phantom measurements. The points characterizing the 27 phantoms are not shown because they have no relevance per se. But they correspond to values of $d$ from which the lines $\mathrm{d}=$ const. are obtained by interpolation. Owing to the errors in measurement and the limited number of available points this interpolation is not very accurate. In particular it does not allow one to decide what the exact shape of the lines actually is. The data might be better represented by curves instead of straight lines.

The intended clinical application of this method would consist of determining $\mathrm{F}$ and $\mathrm{P}$ for a biopsy of a given tumor and then looking for the corresponding value of $d$ in fig. 5 . Comparing fig. 4 and 5 one must feel tempted to conclude that, for most tumors, this can not be done with acceptable accuracy due to the tissue inhomogeneity. Fortunately the situation is not as desperate because the rectangles of fig. 4 overestimate the uncertainty : owing to the anticorrelation between $F$ and $P$ the values occurring really are close to the diagonal of the rectangles the slope of which is not far from that of the curves $d=$ const.. Taking as an example the tumor $U$ one sees that the rectangle representing the standard deviation covers values of $d$ ranging from about $1.3 \mathrm{~mm}$ to $8 \mathrm{~mm}$. The diagonal, however, coincides virtually with the line $d$ $=2 \mathrm{~mm}$ which is therefore the true value of the penetration depth in this tumor. The coincidence is not always as perfect as in this example but in any case the error is reduced considerably. The anticorrelation between $F$ and $P$ is readily interpreted by variations of the scatterer concentration from one sample to another.

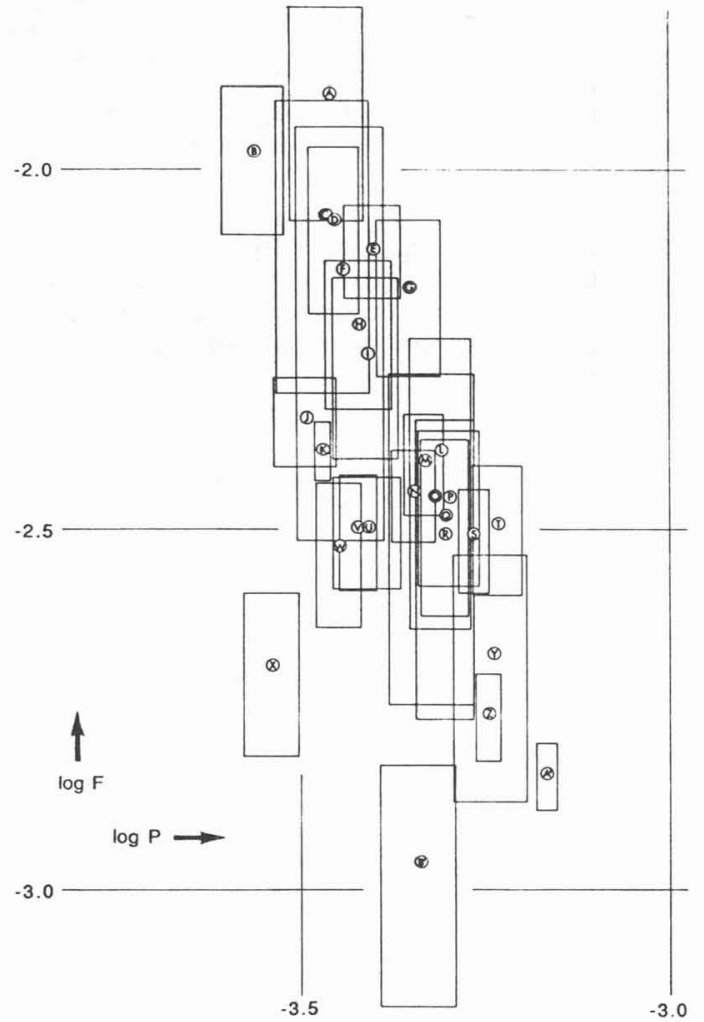

Fig. 4. Means and standard deviations of the optical characteristics obtained in tumor measurements. Colo-rectal tumors : BEFHIJKNOPQSVWX, liver tumor : V, abdominal tumor : $\mathrm{L}$, breast tumors : $\mathrm{TZ}$, gliomas : CGRYB', sarcomas : AD, metastases : MA'.

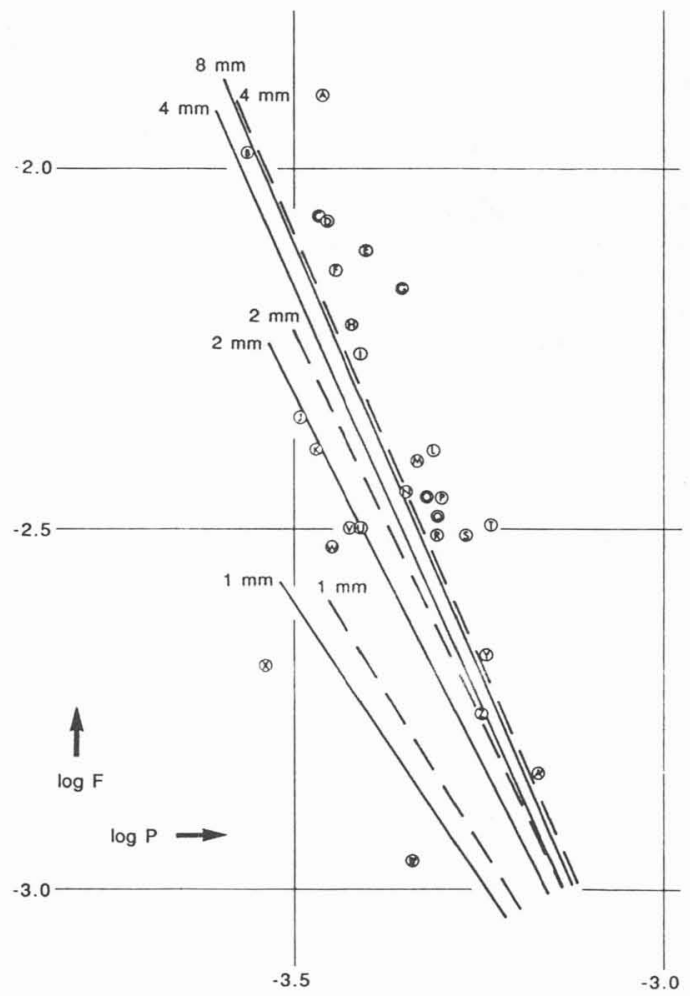

Fig. 5. Relationship between $\mathrm{d}$ and F, P. D $=24$ $\mathrm{mm}$ : full lines, $\mathrm{D}=6 \mathrm{~mm}$ : dashed lines. 